\title{
GSM/GPS based Device Switching with Fingerprint Module Integration using Arduino
}

\author{
Madhu R. \\ PG Scholar, \\ Dept. of ECE \\ Sri Jayachamarajendra \\ College of Engineering \\ Mysore, India
}

\author{
U.B. Mahadevaswamy, PhD \\ Associate Professor, \\ Dept. of ECE \\ Sri Jayachamarajendra \\ College of Engineering \\ Mysore, India
}

\begin{abstract}
With the advancement in wireless technology, many tools have been developed to control a device from a remote location. These tools eliminate the need of physical availability of a person for controlling the device manually. Generally GSM and GPS technology is used in these tools to locate and control a device. But the tools which use only these technologies for their operation are highly insecure and inefficient. This paper proposes an alternate approach for wireless control of a device by incorporating a fingerprint identification module along with GPS and GSM modules. The fingerprint module increases the authenticity of the device and enables multiple users to control the device. These modules are integrated to a simple Arduino microcontroller to demonstrate various functionalities. The proposed approach finds its application in the various fields like automobiles, agriculture, etc.
\end{abstract}

\section{Keywords}

GSM, GPS, fingerprint identification module, Arduino microcontroller, LCD

\section{INTRODUCTION}

In today's modern era, the amount of time required to perform a task plays an important role in day-to-day activities of a human being. In the present scenario, tools are mainly designed to control the equipments through automation and wireless technology. Equipments which have the capability to control a device wirelessly can be easily maintained and they respond at a fast rate compared to the manual operation of the equipments[1]. They also provide high safety and feasibility to the equipment user[2].

This paper focuses on designing a system that integrates fingerprint identification module along with GSM and GPS module to the microcontroller. In today's busy life, a person cannot monitor a device all the time. Hence that person has to take help of wireless technology to keep track of the required device. This remote access of a device is made possible with the help of GPS/GSM based technology[5]. Thus with the increasing interest in the wireless and GSM technology, this paper demonstrates a simple, cost-effective, multipurpose design to control the on-off mechanism of different devices in the field via short message service (SMS)[6].

A simple motor starter application not only requires an automatic on-off mechanism, but also requires safety control measures so that only trusted persons can access the device manually in the absence the device owner. This facility is provided by integration of the fingerprint identification module to the microcontroller[10]. The fingerprint module allows only trusted and authenticated users to access the device. The main feature of fingerprint is the uniqueness in the persons thumb impression[7]. The fingerprint identification technique is used as a barrier in this project, so that unauthenticated persons will not be provided the access[8].

The application of GSM/GPS based device monitoring and switching is not limited to agricultural purposes. It has also found useful in many applications like controlling and monitoring the access to an automobile like a car[9]. The finger-print sensor device can be incorporated also in a car, thereby we can allow only adults to use the car and proper safety can be provided. The GPS also helps us to remotely locate the car and perform the action according to our requirements.

The rest of this paper is organized as follows. In Section II, previous work has been discussed. In Section III, an alternative model for device switching is proposed. In Section IV, various AT commands required for sending and receiving messages are discussed. Section V discusses about flow of implementation. In Section VI, the result of the proposed design is analyzed. In Section VII, the paper is concluded.

\section{PREVIOUS WORK}

Many articles have been published on design and development of a control system which can be used to control a device from a remote location[3]. But the existing designs mainly concentrate on controlling a device from a remote location and do not allow a third person to gain access of the device[4]. In case there is a problem in the remote device, then the owner of the device has to be present at the remote location to correct the fault. And also in the case when an intruder tries to access the device, the existing system does not have any security measures to stop the intruder.

\section{PROPOSED DESIGN}

In this paper an alternative design has been proposed to increase the security features of the device by integrating a fingerprint module with the Arduino microcontroller. The proposed design is an extended approach for automatic control of the device. Fig. 1 shows the block diagram of the proposed design. The proposed design uses GSM/GPS based module to track the device and to provide access to a person in a remote location. 


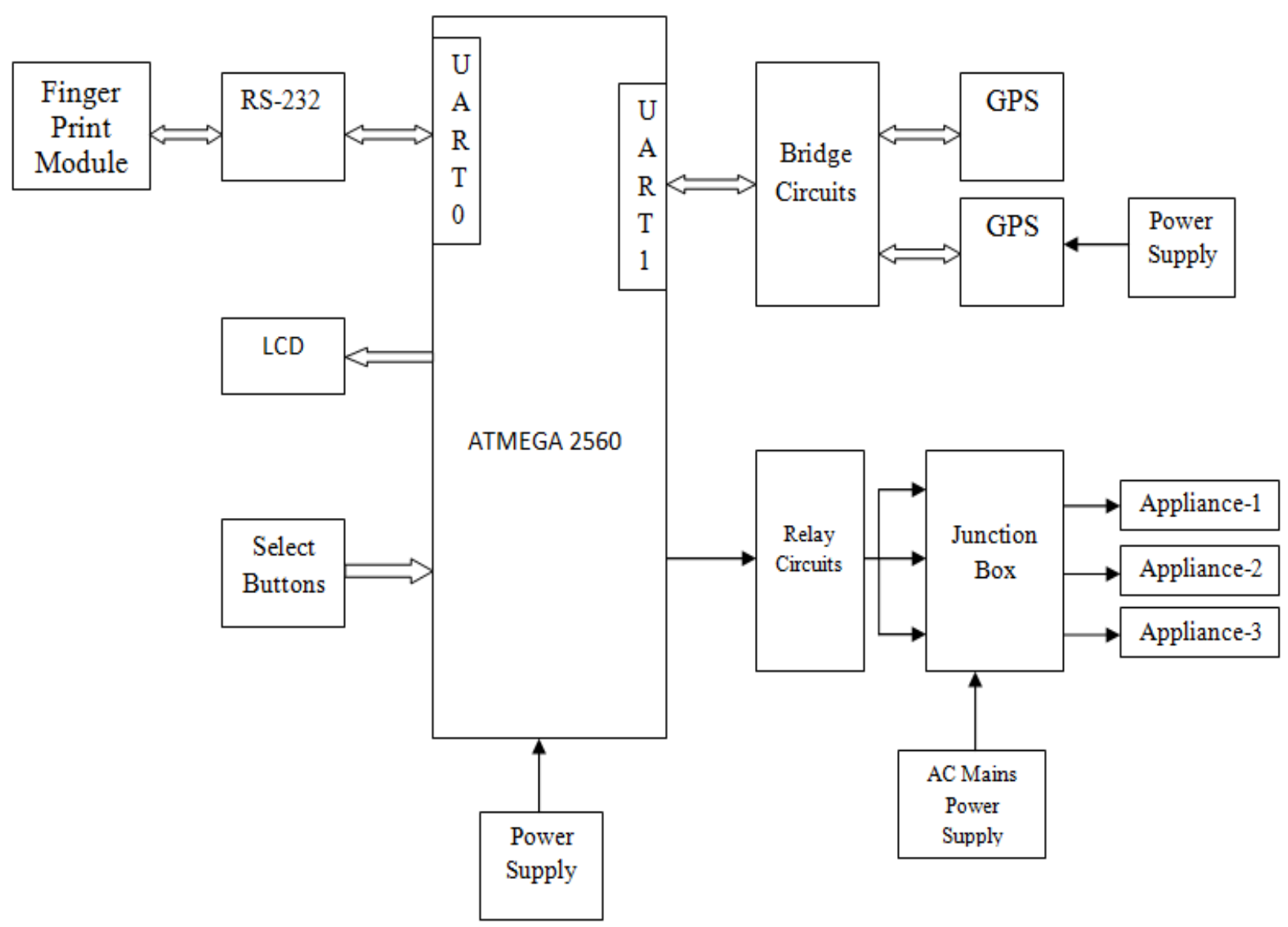

Fig 1: Block diagram of proposed design

The design involves incorporation of a fingerprint identification module which provides high security and authentication features. Inclusion of this module along with GSM and GPS module helps us to detect and correct the various faults in the device at a faster rate. Various components required for this design implementation are described in the following sub-sections.

\subsection{GSM Module}

GSM module facilitates functionalities like sending and receiving messages on mobile phone. The GSM module contains an antenna for receiving signal from the network through the user's cell-phone. This GSM module is programmed with AT commands for communication. Here the serial communication with the microcontroller is done through receiver (RX) and transmitter (TX) pins. AT commands are used to check the SIM status, signal strength and connection.

\subsection{GPS Module}

GPS is an acronym of Global Positioning System and it is used as a navigation system to find the locality of a device or a place accurately. GPS helps us to the find the exact location of the device and thereby theft of the device is minimized.

\subsection{Arduino Microcontroller}

In the proposed design we have used Arduino Mega 2560 microcontroller board which is based on ATmega2560. All the modules are controlled by microcontroller and it acts as a driving force in obtaining the desired output.

\subsection{Fingerprint Module}

In this design a fingerprint sensor module is interfaced and powered through Arduino board. The user can use the Arduino IDE to enroll his fingerprint into the ATmega2560 microcontroller.

\subsection{Liquid Crystal Display (LCD)}

A LCD is a tool used for visual display of the output and it follows the properties of light modulation for its display. An LCD is required in this project to display various messages to user and thus making the device convenient. The various types of messages include a welcome message or an access request message or a permission granted message.

\subsection{Relay circuit and Junction Box}

Relay is an electronic component that can be used as a switch to control several circuits by one signal. In this project a junction box is used for real time implementation of the proposed design. Various appliances are connected to the junction box and they are operated with the AC power supply.

\section{AT COMMANDS AND ARDUINO}

The instructions that are used to control a modem are known as AT commands. Abbreviation of AT is ATtention. Every command line that is used to control a modem begins with the keyword "AT". For every successful command, the modem will answer with an OK signal, whereas an undefined command will not succeed and generate an error.

Various AT commands used in this design are AT+CNMI, $\mathrm{AT}+\mathrm{CMGS}, \mathrm{AT}+\mathrm{CMGF}$. The command AT+CNMI is used for new message indication to terminal equipment. This AT 
command chooses the method to indicate the reception of message in the network is for DTE while it is enabled. The command AT+CMGS is used for sending and writing the message. The command AT+CMGF is used represent the message format. The representation format of short messages from the modem is controlled by this command.

In the present days, USB is used to program Arduino boards and USB to adapter chips are used for its implementation. A typical Arduino IDE supports $\mathrm{C} / \mathrm{C}++$ programming and it consists of two functions that can be compiled and linked. The arduino converts the main () program into a cyclic executable program. Programming in Arduino can be divide into two parts namely loop and setup function. Setup( ) function is executed once during the beginning of a program and settings can be initialized using this function. Loop( ) function runs continuously until the board is turned off. The executable file can be converted into text file and can be represented with hexadecimal values using Arduino IDE program. These converted values can be loaded in the board's firmware by a loader program.

\section{IMPLEMENTATION OF THE DESIGN}

The process of implementation starts with the initialization of LCD and GSM modem. After all the components are initialized, the user can directly control the device by sending a text message. This design also allows a person near the device to access it, if that person is given permission by the authenticated user. The person near the device terminal, inputs his fingerprint in the fingerprint sensor. If the fingerprint is a valid image, then a message will be sent to the device owner for access permission. If the owner of the device sends an access granting message, then the person near the device can control it manually. But if the fingerprint image is found invalid, the LCD will show "invalid user" message and access will not be given to that person.

The fingerprints are taken and stored in the database using Arduino software. The Arduino Software allows user to enroll as many fingerprints as possible. The user has the permission to add or delete any fingerprint in the database. In order to use fingerprint module and GPS module, separate software's must be added to Arduino software library. The user accessing the device manually must press logout button after he finish using it. When a person is using the device manually, the owner of the device cannot turn ON/OFF the device automatically from a remote location. The screen monitor of the Arduino compiler can be used to monitor and analyze the result. Fig.2 shows the flowchart for the proposed design.

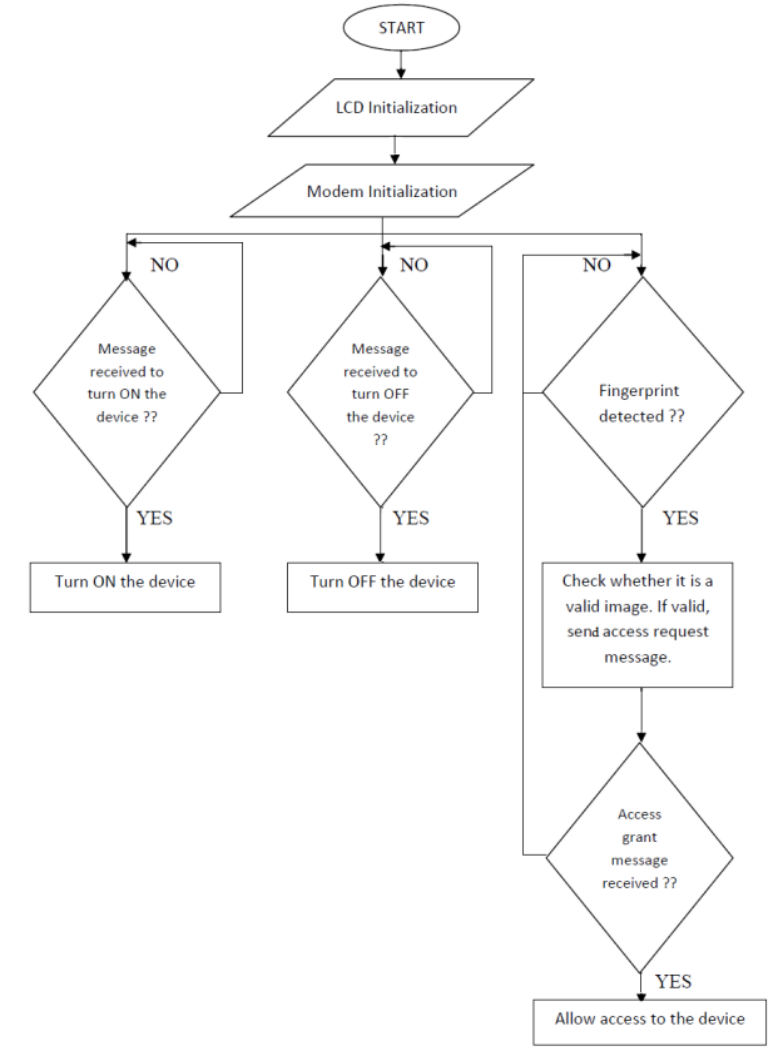

Fig 2 Flowchart of Proposed Design

\section{RESULT ANALYSIS}

The first step is to interconnect all the modules and provide proper supply voltage to the devices. LCD displays the operating condition of the device and also indicates the status of other devices. We have used a fan as Appliance-1, a bulb as appliance-2 and an AC motor as Appliance-3. All these devices can be controlled simultaneously by the user.

The following snapshots are taken from system LCD and can be used in result analysis. Fig. 3 shows the welcome message displayed on LCD when the device is powered ON. Now when the user presses button 1 in push buttons board, the LCD will display a message asking user to input a fingerprint on the fingerprint module as shown in Fig.4

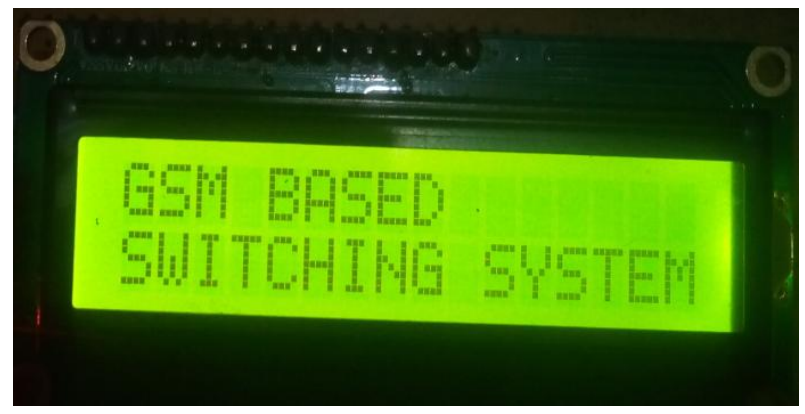

Fig 3 Welcome message on LCD when device is turned ON 


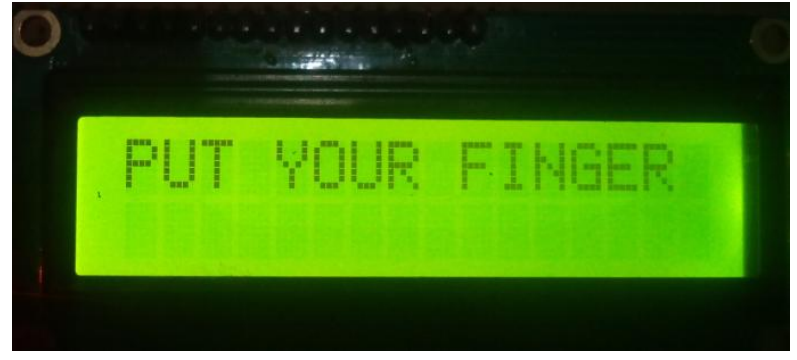

Fig 4 Device asking for user input

Now the microcontroller will wait for fingerprint image. When the user provides a fingerprint, the microcontroller checks its database to see whether it is valid or not. If the fingerprint is valid, a message will be sent to owners mobile requesting for access. Now the LCD will display access requesting message as shown in Fig.5. Now if the user sends an access granting message, then LCD will display corresponding message as shown in Fig.6. The device owner is responsible for providing the access to other users by sending the access granting message.

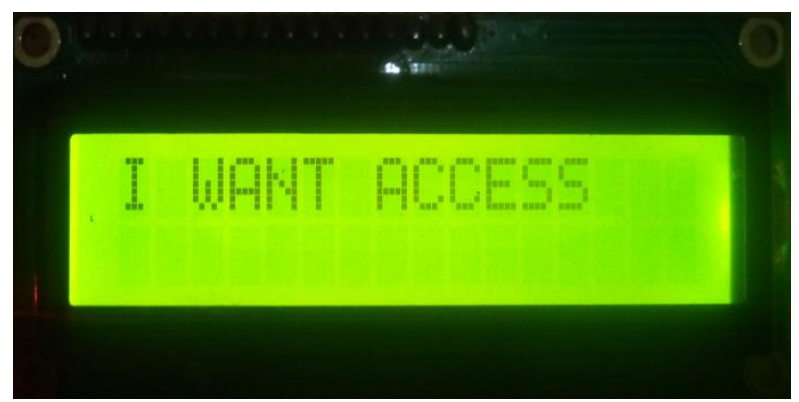

Fig 5 User requesting for device access

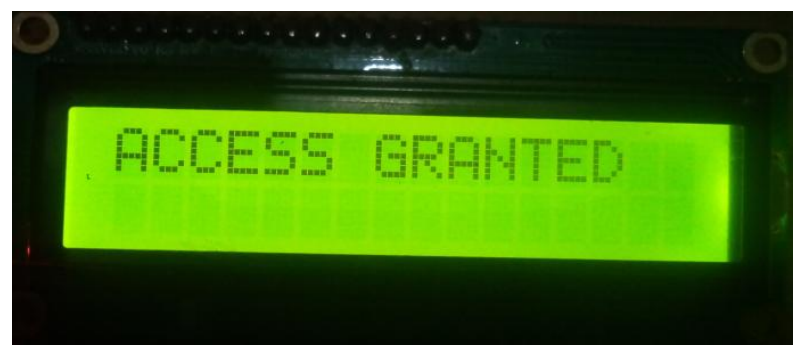

Fig 6 Snapshot of LCD showing access granted message

Now the user can control the all the devices simultaneous. Fig.7 and Fig.8 shows the operating condition of Appliance-1.

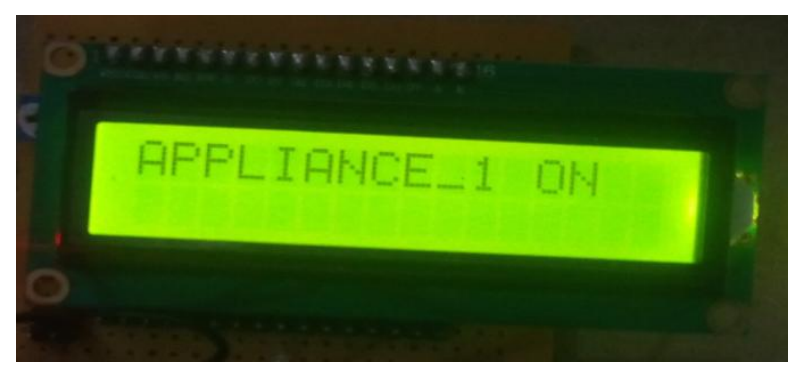

Fig 7 LCD indicating the ON status of Appliance 1

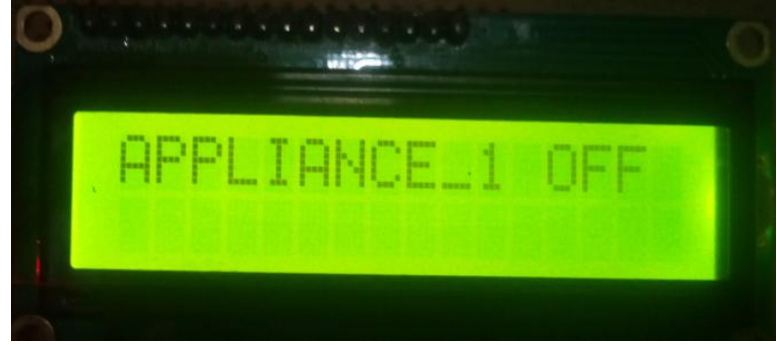

Fig 8 LCD indicating the OFF status of Appliance 1

The screen monitor of Arduino software can also be used to analyze the result and draw a conclusion. Fig.9 shows a snapshot of screen monitor requesting the access for controlling the devices. Fig. 10 shows the demonstration of the proposed design with real-time implementation and depicts that all devices can be turned ON simultaneously. Table 1 shows the comparison between the existing and the proposed design.

\begin{tabular}{|c|c|c|}
\hline COM13 & & 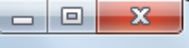 \\
\hline l & & Send \\
\hline $\begin{array}{l}\text { AT+CMGF }=1 \\
\text { AI+CMMI=2, } \\
\text { Found finge } \\
\text { Waiting for } \\
\text { Image taker } \\
\text { Image conve } \\
\text { Found a pri } \\
\text { Found ID } \# 3 \\
\text { Found ID } \# 3 \\
\text { AI+CMGF }=1 \mathrm{AI}\end{array}$ & $\begin{array}{l} \\
\text { of } 32839 \\
\text { of } 32839 \\
1653 " I \text { WANT ACC }\end{array}$ & \\
\hline ( Autoscroll & No line ending $\longrightarrow$ & 9600 baud \\
\hline
\end{tabular}

Fig 9 Snapshot of Screen monitor

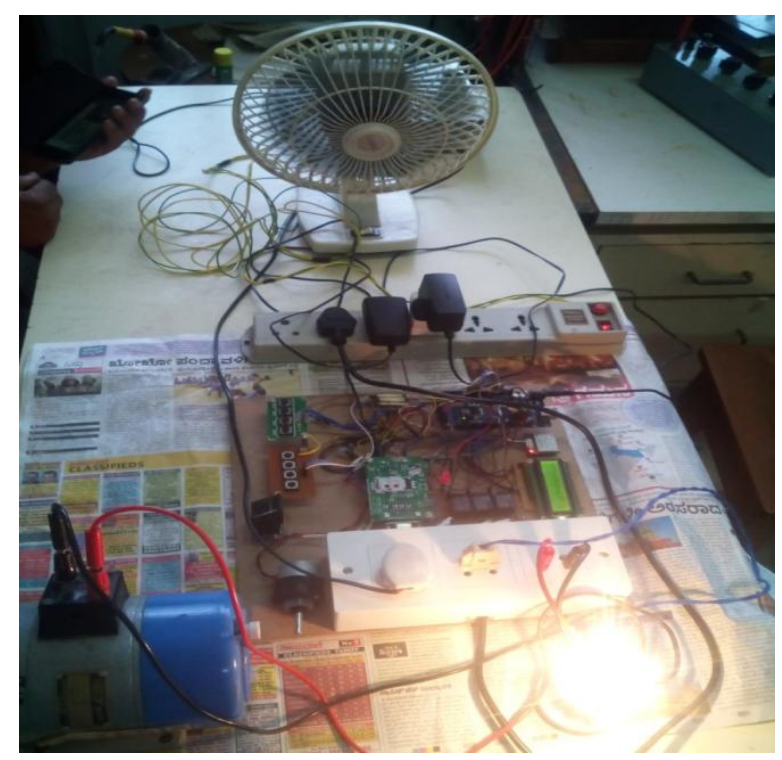

Fig 10 Demonstration of the proposed design 
Table 1 Comparison between existing and proposed design

\begin{tabular}{|c|l|l|}
\hline Parameter & \multicolumn{1}{|c|}{ Existing Design } & Proposed Design \\
\hline Security & Less secure[4],[5] & $\begin{array}{l}\text { More secure due to } \\
\text { added fingerprint } \\
\text { identification } \\
\text { module }\end{array}$ \\
\hline Accessibility & $\begin{array}{l}\text { Only single user can } \\
\text { have the access to the } \\
\text { device[10] }\end{array}$ & $\begin{array}{l}\text { Multiple users can } \\
\text { access the device by } \\
\text { taking permission } \\
\text { from the device } \\
\text { owner }\end{array}$ \\
\hline Flexibility & $\begin{array}{l}\text { Less flexible and } \\
\text { cannot be used for } \\
\text { multiple applications } \\
{[8]}\end{array}$ & $\begin{array}{l}\text { Highly flexible and } \\
\text { can be used for } \\
\text { various applications } \\
\text { like Automotive, } \\
\text { Irrigation, etc }\end{array}$ \\
\hline
\end{tabular}

\section{CONCLUSION AND FUTURE WORK}

In this paper an alternative approach for device switching which combines fingerprint identification technique with GSM and GPS functionalities has been proposed. The device switching from remote location removes the necessity of the person to be present near the device to operate it. This approach allows more than one person to control the device functionality and the authentication facility provided by the fingerprint sensor helps to reduce the fault correction time.

The Arduino board used in this model is least expensive and can be implemented in various applications. The application of device switching is not limited to control device from a long distance, but it can also be used in automobile applications. The proposed design not only provides switching functionality, but also provides the exact location of the device. Hence theft of the device can easily be detected.

In the future work cloud computing can be included to this project so that every activity performed on the device can be closely monitored. This reduces the need for storing all the log-in information in the computer storage.

\section{REFERENCES}

[1] "Vehicle Location Finder Using Global Position System and Global System for Mobile", M.F. Saaid, M.A Kamaludin, M.S.A. Megat Ali, IEEE, Aug-2014.

[2] "Automobile Anti-theft System Based on GSM and GPS Module", Hu Jian-ming, Li Jie, Li Guang-hui, IEEE, 2012.

[3] Parvathy.V.Menon, Anoop.T.K, Vijesh.E.P and R.Satheesh "GSM based Device Switching", IJETT, vol 4, April 2013

[4] "Design and Prototype Implementation of SMS Based Home Automation System", H. ElKamchouchi, IEEE, 2012.

[5] "Design and Implementation of an SMS Based Home Security System", Biplav Choudhury, Tameem S. Choudhury, Aniket Pramanik, Wasim Arif, J. Mehedi, IEEE,2015.

[6] Mohd Helmy Abd Wahab, Norzilawati Abdullah, Ayob Johari, Herdawatie Abdul Kadir, "GSM Based Electrical Control System for Smart Home Application", Journal of Convergence Information Technology, Vol 5, no. 1, February 2010.

[7] "Fingerprint Identification and Its Applications in Information Security Fields", ZHOU Shihai, LU Xiangjiang, IEEEE, 2010.

[8] "Biometric Smart Attendance Kit with Fingerprint Scanner by Using Microcontroller", Fahad-Bin-Mazhar, Oli Ahamed, Md.Rasedujjaman, IEEE, Nov- 2015.

[9] "Real Time Vehicle Tracking System Based on ARM7 GPS and GSM Technology", Pradip V Mistary, R H Chile, IEEE, 2015

[10] "Design of Small Smart Home System Based on Arduino", Andi Adriansyah, Akhmad Wahyu Dani, IEEE, 2014 